\title{
CAPTURE
}

\section{SOCIAL CRITICISM IN THE MISTER FRIMEN ANIMATED SERIES}

\author{
Riska Ristiasari ${ }^{1}$ dan Hendra Kaprisma² \\ 1 Universitas Indonesia (UI), Jakarta, Indonesia \\ 2 Universitas Indonesia (UI), Jakarta, Indonesia \\ E-mail: kaprisma@ui.ac.id
}

\begin{abstract}
Social criticism is generally comprised of individuals' ideas and opinions of societal problems that bring changes. Individuals can express their opinions through various media, including animated films. The animated series Mister Frimen created by Pavel Muntyan, Vladimir Ponomarev, Anatoly Dobrozan, and Vadim Demchog are notoriously sarcastic. The sarcastic remarks given by the main character are always about current problems in Russian society. This study focuses on the way the animated series Mister Frimen expresses social problems. This article uses intertextual theory and discourse analysis to analyze every message and symbol and how the messages are generated. The results show that each scene in Mister Frimen contains symbols illustrating social criticism messages about the situation of Russian society. Nonetheless, satire/social criticism offers suggestions for establishing societal peace and prosperity.
\end{abstract}

Keywords: Intertextuality, social criticism, film animation, and Russia

ABSTRAK

Kritik sosial umumnya berisi pendapat dan opini seseorang tentang suatu masalah yang terjadi dalam sebuah masyarakat yang biasanya bersifat membawa perubahan. Seseorang dapat menyampaikan pendapatnya melalui sebuah media, salah satunya yaitu film animasi. Serial animasi berjudul Mister Frimen yang dibuat oleh Pavel Muntyan, Vladimir Ponomarev, Anatoly Dobrozan, dan Vadim Demchog terkenal sarkastis. Pesan-pesan sarkasme yang disampaikan oleh tokoh utamanya selalu membahas permasalahan yang terjadi dalam masyarakat Rusia. Penelitian ini fokus pada bagaimana permasalahan sosial diungkapkan dalam serial animasi Mister Frimen. Untuk membaca setiap pesan-pesan dan simbol yang ada dan bagaimana pesan itu terbentuk, peneliti menggunakan teori intertekstual dan analisis wacana sebagai metodenya. Hasil penelitian menunjukkan bahwa setiap adegannya dalam Mister Frimen terdapat simbol-simbol yang menyampaikan pesan-pesan yang terselip kritik sosial mengenai keadaan masyarakat Rusia. Meskipun begitu, di dalam sindiran/kritik sosial tersebut terdapat saran untuk mencapai kedamaian dan kesejahteraan dalam masyarakat.

Kata kunci: Intertekstualitas, kritik sosial, film animasi, and Rusia

\section{PENDAHULUAN}

Nikolay Chernyshevsky (1828-89) dianggap sebagai kepala kritik tahun 1860an, di mana kritik sebagai senjata dalam perjuangan melawan Tsarisme dan emansipasi para budak. Kritik di Rusia memiliki fungsi yang jauh lebih luas daripada di Barat, sehingga dapat diketahui bahwa kegiatan mengenai kritik sudah ada sejak abad-19 saat karya sastra mulai 
digunakan untuk menghindari adanya sensor pemerintah yang melarang kebebasan berpendapat (Wellek, 1992). Pada umumnya, kritik lahir dari pemikiran kritis seseorang, sehingga kritik sosial merupakan sebuah sarana komunikasi yang berisi tentang masukan, ide, dan pendapat yang dihasilkan oleh seseorang serta berguna untuk mengontrol tatanan sosial. Karya sastra di Rusia memiliki peranan kuat dalam sebuah perubahan. Oleh karena itu, banyak sastrawan yang menggunakan karyanya sebagai media kritik terhadap pemerintahan mengingat adanya pengekangan bebas berpendapat dan berekspresi dalam menyampaikan sebuah kritik secara langsung, sehingga kritik sastra di Rusia isinya jarang yang benar-benar mengkritik tentang sastra (Wellek, 1992). Selain karya sastra, beberapa media juga dapat digunakan sebagai wadah untuk menyampaikan sebuah kritik, salah satunya yaitu animasi. Dan, dapat disebut juga kartun yang membawa pesan kritik sosial (Sugihartono, 2010).

Dalam perkembangannya, animasi awalnya digunakan sebagai hiburan saja sehingga cerita pada film animasi yang dihasilkan saat masa kekaisaran pun diangkat dari dongeng dan karya sastra. Namun, setelah memasuki periode awal saat mereka mulai mengenal kartun animasi dengan bantuan teknologi, walaupun ceritanya masih berdasarkan pada dongeng dan literatur anak-anak, fungsi utama dari animasi itu sendiri mulai berubah. Pada tahun 1930-an pemerintahan Uni Soviet yang bekerja sama dengan para animator mulai menggunakan kartun dan animasi mereka sebagai media untuk kepentingan negara (Briggit, 2006). Secara tidak langsung, isi cerita dan pesan yang disampaikan dari animasi tersebut berisikan ideologi dan propaganda politik. Oleh karena itu, animasi Soviet sangat berbeda jika dibandingkan dengan animasi Barat.

Selain berisi ideologi dan propaganda yang ditanamkan oleh pemerintah, animasi Soviet juga digunakan para animator untuk mengkritik kinerja pemerintah dan kehidupan sosial dengan gaya satirnya serta dikemas dengan sedemikian rupa, di mana pada saat itu hak kebebasan berpendapat dan berekspresi dilarang. Namun, saat memasuki era Khruschev Thaw (Era Pencairan) mulai banyak bermunculan animasi dan kartun yang secara terang-terangan berisikan tentang sindiran-sindiran satir seputar kehidupan sosial, karena saat itu pengekangan bebas berekspresi dan mendapatkan informasi mulai mengendur (Pontieri, 2006).

Animasi pada masa pemerintahan Federasi Rusia saat ini juga banyak digunakan para animator untuk menyampaikan sebuah opini dan kritik sosial yang berasal dari hasil pemikiran 


\section{CAPTURE}

kritisnya terhadap permasalahan sosial di sekitarnya. Namun, kritik sosial yang disisipkan dalam isi cerita dan bentuk gambarnya dibuat lebih menarik, karena teknologi yang dipakai sudah maju dan lebih praktis. Lebih lanjut lagi, pengaruh animasi saat ini dapat dikatakan semakin kuat dalam pembentukan perubahan dan menggiring sebuah opini publik secara luas, karena adanya kemudahan akses yang dapat dijangkau oleh para pengguna internet. Salah satu contoh animasi populer di kalangan pengguna internet sekarang adalah Mister Frimen, serial animasi karya dari Pavel Muntyan, Vladimir Ponomarev, Anatoly Dobrozan, dan Vadim Demchog yang hanya dirilis di YouTube dan rilis pada tahun 2009 hingga saat ini.

Mister Frimen merupakan animasi yang dapat membawa perubahan besar, karena pesan-pesannya ditampilkan menggunakan bahasa yang sederhana dan mudah diterima oleh para kalangan remaja. Melalui karyanya, Muntyan dan rekanrekan mencoba menyampaikan pemikiran kritisnya mengenai permasalahan sosial yang ada, mulai dari prostitusi, nilai-nilai filosofis kehidupan, moralitas, kebebasan, dan hierarki sosial. Hal itu dikemas dengan simbol-simbol gambar dan kata-kata yang terbilang cukup kreatif, sehingga dapat dikatakan bahwa konten-konten yang disajikan di dalamnya bertujuan untuk mendorong para penontonnya supaya membuka mata dan belajar lebih dalam mengenai nilai-nilai hakiki yang ada di dunia ini (Asmolov, 2010).

Oleh karena itu, permasalahan yang akan dibahas dalam penelitian ini adalah bagaimanakah kritik sosial di Federasi Rusia ditampilkan pada serial web animasi Mister Frimen.

\section{TINJAUAN PUSTAKA}

\subsection{Tinjauan Hasil Penelitian}

Ada beberapa penelitian yang pernah mengkaji topik serupa atau yang berkaitan dengan topik ini, yaitu:

Pertama, penelitian yang ditulis oleh Laura Poentieri pada tahun 2006 yang berjudul Russian Animation of The 1960s and The Khrushchev Thaw. Pada penelitian ini, peneliti membahas fungsi dan gaya animasi Soviet yang berkembang selama periode Thaw di bawah Khrushchev (1953-1964), dan menunjukkan bagaimana tren radikal dan eksperimental yang muncul pada waktu itu dikembangkan lebih lanjut pada tahuntahun awal di bawah Brezhnev (akhir 1960an) sebelum apa yang disebut 'Stagnansi' telah sepenuhnya terjadi. Animasi Soviet dalam fase perintisnya pada tahun 1920-an telah terikat erat dengan karya-karya avantgarde (karya seni atau para seniman yang dianggap inovatif) dan propaganda, terutama ditujukan kepada masyarakat dewasa. Pada masa pemerintahan Stalin, animasi telah dikurangi untuk menghibur penonton anak-anak dengan film-film yang 
gayanya sebagian besar berasal dari Disney yang homogen. Liberalisasi di bawah Khrushchev berarti bahwa media ini dapat merebut kembali statusnya sebagai bentuk seni utama; beberapa teknik dan strategi gaya tahun 1920-an dihidupkan kembali dan dikembangkan. Pada saat yang sama, animasi bergabung dengan proses umum kritik sosial, sering menggunakan sindiran atau manipulasi canggih dari keterkaitan antara teks verbal dan teks visual. Untuk memunculkan konteks agar dapat memahami perubahan yang terjadi pada 1960-an, terdapat beberapa bab yang masing-masing menjelaskan tentang sejarah animasi Soviet, bagaimana peran animasi di tahun kekuasaan Khrushchev, dan sampai kepada penelitian tentang bagaimana nasib dari animasi Soviet pada akhir 1960-an. Hal itu menunjukkan bagaimana beberapa animator dapat melanjutkan pekerjaan yang telah dimulainya pada masa pemerintahan Khrushchev. Hasilnya adalah, disertasi ini memberikan studi kasus tentang dinamika interaksi antara seni dan kekuasaan.

Yang kedua yaitu penelitian yang ditulis oleh Gregory Asmolov pada tahun 2010 berjudul Russia: Online Cartoon Character - Mr. Freeman - Deconstructs Reality, Mocks Netizens. Asmolov dalam penelitiannya membahas mengenai pesanpesan apa saja yang ingin disampaikan oleh animator. Dalam artikel ini, Gregory menyatakan bahwa sesungguhnya kartun animasi ini tidak memiliki pesan mengenai politik, tetapi para animatornya berusaha menyampaikan pesan-pesan tentang filosofis kehidupan, moralitas masyarakat dan menggambarkan tentang kekosongan yang terjadi dalam hidup manusia, termasuk masalah konsumerisme dan saling menertawakan keadaannya satu sama lain. Selain itu, artikel ini juga membahas tentang dampak dan reaksi apa yang muncul pada generasi muda setelah kartun animasi ini mulai diunggah atas kepopulerannya di kalangan para pemuda. Hasilnya adalah bahwa animasi ini sukses mempengaruhi para penontonnya untuk mengajak mereka melakukan perubahan baru untuk kehidupannya sendiri.

Yang ketiga, penelitian ditulis oleh Alfiansyah Zulkarnain pada tahun 2019 yang berjudul Kajian Semiotika Intertekstualitas Film Ralph Breaks the Internet. Penelitian tersebut membahas mengenai bagaimana intertektualitas berpengaruh dalam komposisi tanda, sehingga dapat menjadi sebuah model kerangka teoritis untuk menghasilkan narasi sebagai teks. Dalam penelitiannya, Alfiansyah menggunakan metode kajian kualitatif untuk membedah bagaimana teks yang dihasilkan dalam film tersebut dapat dibaca sampai pada tahap semiosis. Untuk melihat bagaimana intertekstualitas mempengaruhi interpretasi tanda pada tingkatan-tingkatan proses semiosis, ia 


\section{CAPTURE}

menggunakan teori Intertekstualitas yang digabungkan dengan teori Skema Semiosis oleh Sanders Pierce sebagai model. Artikel ini membantu penulis dalam menganalisis bagaimana intertekstualitas dapat mempengaruhi hadirnya sebuah tanda dan simbol dalam film animasi baik itu dari naskah maupun tanda secara visual yang muncul pada film animasi Mister Frimen.

Yang keempat, ditulis oleh Teerapong Serisamran pada tahun 2018 yang berjudul Applying Intertextuality Between Film and Painting for Filmmaking. Penelitian ini membahas mengenai konsep intertekstual antara film dan lukisan yang diekstraksi menjadi pengetahuan yang digunakan oleh para siswa dalam membuat sebuah film. Tujuan dari penelitian ini adalah untuk mempelajari penerapan intertekstualitas antara film dan lukisan untuk pembuatan film. Penelitian ini adalah penelitian kualitatif yang mempelajari tentang konsep Intertekstualitas antara film dan lukisan yang diekstraksi menjadi pengetahuan yang digunakan di kelas bagi siswa untuk mencoba membuat film mereka sendiri. Penelitian ini berisi studi dari dokumen-dokumen, tur pendidikan di museum, dan menganalisis siswa menggunakan pengetahuan untuk mengajukan pembuatan film mereka. Hasilnya menunjukkan bahwa ada empat pola intertekstualitas antara film dan lukisan yang biasanya muncul dalam film: penghormatan, kiasan, kutipan, dan parodi.
Intertekstualitas dapat disajikan dalam dua aspek yaitu penyajian bentuk seni yang digunakan sebagai inspirasi dan alat untuk menciptakan gambar dan cerita film, sedangkan penyajian konten adalah narasi yang berkaitan dengan lukisan atau beberapa bagian kehidupan para seniman. Pengetahuan tentang lukisan dapat diterapkan untuk pembuatan film melalui mise-en-scène (misalnya komposisi, arah seni, pencahayaan dan warna) Siswa dapat menerapkan konsep intertekstualitas antara film dan lukisan ke dalam proses pembuatan filmnya. Homage adalah pola intertekstualitas yang paling banyak digunakan, sementara kutipan dan parodi adalah yang kedua. Selain itu, siswa dapat menerapkan pengetahuan tentang intertekstualitas antara film dan lukisan yang ditunjukkan dari mise-en-scène dalam film karya mereka.

\subsection{Teori Intertekstual}

Istilah mengenai intertekstual pertama kali diperkenalkan oleh Julia Kristeva dalam esainya yang berjudul World, Dialogue and Novel (1966) dan The Bounded Text (1966-1967). Menurut Kristeva, teks tidak berdiri sendiri dan bukan murni hasil dari pemikiran sang penulisnya, karena dia percaya bahwa sebuah teks memiliki relasi-relasi dari teks yang sudah ada sebelumnya dan berasal dari teks lain yang sudah dikompilasi dan dikombinasikan dengan sedemikian rupa 
(Kristeva, 1980). Lebih mudahnya adalah satu teks hadir, karena terbuat dari kutipankutipan teks lain yang sudah diasimilasikan, sehingga menjadi sebuah satu kesatuan. Secara tidak langsung, konsep dari intertekstual adalah sebuah karya tidak ada yang original di dunia ini dan semuanya saling sambungmenyambung. Oleh karena itu, dapat dilihat bahwa intertekstualitas memamerkan beragam wacana yang digunakan dalam periode sejarah yang berbeda. Lebih lanjut lagi, suatu teks atau wacana jika diinterpretasikan akan saling bergantung dengan teks-teks yang lain. Baginya, teks juga bukan merupakan suatu hal yang terpisah, tetapi ia terbentuk karena adanya suatu budaya di mana teks tidak dapat dilepaskan dari tekstualitas sosial dan budaya yang merupakan teks itu dibuat (Prayer Elmo Raj, 2015).

Konsep yang diperkenalkan oleh Kristeva ini sebenarnya hasil dari pengamatannya mengenai konsep dialogisme Bakhtin. Secara tidak langsung, intertekstualitas Kristeva ini merupakan pengembangan dari pemikiran Bakhtin. Menurut Bakhtin, dialogisme didasarkan pada bagaimana manusia menggunakan bahasa dalam konteks atau situasi sosial tertentu. Bakhtin menekankan pada keberbedaan bahasa: pada stratifikasi internalnya, pada apa yang ia sebut sebagai polifoni atau heteroglosia koeksistensi dan saling mempengaruhi dari beberapa jenis wacana yang mencerminkan dialek sosial atau kelas dan berbagai generasi serta kelompok umur masyarakat. Bakhtin juga berpendapat bahwa kehidupan sebuah kata terkandung dalam pemindahan dari satu mulut ke mulut lain, dari satu konteks ke konteks lain, dari satu kolektif sosial ke yang lain (Haberer, 2007). Sedangkan, Kristeva lebih menekankan kepada unsur yang paling utama dalam sebuah teks adalah konsep intertekstual (Kuswarini, 2016).

Menurut Kristeva, teks sastra berada pada dua poros yaitu poros vertikal dan horizontal. Poros vertikal menggambarkan koneksi antara teks dengan teks lainnya, baik teks yang terdahulu maupun teks yang akan datang. Sedangkan, poros horizontal mewakili koneksi antara teks dengan pengarang dan pembaca (Kuswarini, 2016).

John Fiske dalam bukunya yang berjudul Television Culture juga membahas mengenai intertekstual dan mengembangkan istilah intertekstual tersebut untuk ranah studi mengenai media massa. Fiske berpandangan bahwa program televisi dibangun secara intertekstual oleh audiens dan bagaimana budaya populer dibaca secara intertekstual (Ott and Walter, 2000). Lebih lanjut, ia menggunakan intertekstualitas untuk menggambarkan cara audiens secara tidak sadar menciptakan makna dengan memanfaatkan pengetahuan luas tentang 
kode budaya yang dipelajari dari teks lain untuk membaca teks tertentu (Ott and Walter, 2000). Hal tersebut dapat dilihat pada penjelasan Fiske mengenai pembagian intertekstual menjadi dua dimensi yaitu intertekstual horizontal dan vertikal.

Horizontal relations are those between primary texts that are more or less explicitly linked, usually along the axes of genre, character, or content. Vertical intertextuality is that between a primary text, such as a television program or series, and other texts of a different type that refer explicitly to it. These may be secondary texts such as studio publicity, journalistic features, or criticisms, or tertiary texts produced by the viewers themselves in the form of letters to the press or, more importantly, of gossip and conversation (Fiske, 2010).

Menurut Fiske, intertekstual horizontal terjadi ketika teks primer berhubungan dengan teks primer lainnya atau teks sekunder berhubungan dengan teks sekunder melalui genre atau jenisnya, karakter, dan konten. Sebaliknya, intertekstual vertikal hadir ketika teks primer berhubungan dengan teks sekunder dan tersier. Teks primer dalam hal ini dapat dimaknai sebagai sumber pertama seperti buku, novel, program televisi, dan yang lainnya. Ketika seseorang menonton film yang ber-genre romantis, maka saat ia menonton film dengan genre yang sama, tetapi dengan judul yang berbeda, ia sudah mengetahui alur dan akhir dari cerita film tersebut. Karena memiliki genre yang sama dan hal inilah yang disebut sebagai intertektual horizontal. Selanjutnya, saat proses pemaknaan teks primer dipengaruhi dan berhubungan dengan teks sekunder misalnya ulasan dari seorang kritikus, wawancara para tokoh dan penulis, berita yang dibuat oleh jurnalis, maka keterhubungan ini disebut sebagai intertekstual vertikal. Selain itu, keterhubungan dengan teks tersier juga termasuk dari intertekstual vertikal. Dalam penjabaran Fiske, hasil interpretasi dari penonton seperti percakapan kabar burung merupakan teks tersier. Oleh karena itu, teks sekunder dan tersier secara tidak langsung membantu pembacaan makna yang ada pada teks primer.

Oleh karena itu, intertekstualitas dari keduanya akan digunakan dalam penelitian ini untuk melihat bagaimana kritik sosial yang muncul pada film ini dipengaruhi oleh berita-berita tentang keadaan sosial yang terjadi saat itu dan juga membantu dalam menunjukkan apakah kritik sosial yang terkandung hadir karena dipengaruhi oleh suatu teks lain atau murni dari hasil pemikiran animator tersebut.

\section{METODE}

Penelitian ini termasuk jenis penelitian deskriptif kualitatif dengan objek kajian berupa film animasi berjudul Mister Frimen. Sampel penelitian adalah episode 59 yang dirilis tahun 2017 dengan teknik purposive sampling.

Berdasarkan akun Youtube Mister 
Frimen dalam versi bahasa Rusia, episode yang telah dirilis sudah sebanyak 32 episode yang terbagi dalam season 1 dan season 2. Namun, untuk penomoran dari setiap episode yang terdapat dalam setiap season-nya tidak saling berurutan. Oleh karena itu, untuk melihat permasalahan sosial yang muncul pada era Federasi Rusia dalam rentang tahun 2011-2019, maka peneliti memilih episode 59 yang dirilis pada tahun 2017 dan terdapat di season kedua. Hal itu yang dijadikan pertimbangan episode 59 yang dijadikan objek kajian.

Adapun teori yang digunakan adalah teori intertekstualitas Julia Kristeva dan John Fiske. Teknik pengumpulan data yang digunakan yaitu metode studi pustaka. Metode ini mengumpilkan informasi dari sumber-sumber pustaka yang berhubungan dengan penelitian dan sumber-sumber yang diunduh dari internet dan film animasi yang diunduh dari situs Youtube.

Analisis terhadap data yang terkumpul dilakukan dengan menggunakan metode analisis wacana. Analisis wacana yaitu bagaimana seseorang atau suatu objek ditampilkan melalui bahasa. Dalam analisis wacana dikenal adanya tiga sudut pandang mengenai bahasa. Pandangan pertama, bahasa dilihat sebagai jembatan antara manusia dengan objek di luar dirinya. Jadi analisis wacana digunakan untuk menggambarkan tata aturan kalimat, bahasa, dan pengertian bersama. Wacana diukur dengan pertimbangan kebenaran/ketidakbenaran menurut sintaksis dan semantik (Eriyanto, 2006). Pandangan kedua memandang analisis wacana digunakan untuk membongkar makna tertentu dan pandangan ketiga yaitu bahasa adalah sebuah ilustrasi dalam membentuk sebuah subjek atau wacana tertentu. Selain itu, bahasa juga merupakan unsur utama dalam pembentukan sebuah proses realitas. Jika lebih jauh lagi, bahasa bukan hanya sebuah alat untuk menggambarkan realitas, tetapi dapat menentukan gambaran mengenai suatu realitas yang nantinya muncul dalam pemikiran masing-masing orang apabila bahasa dilihat dalam media massa (Melvin DeFleur dan Sandra Ball-Rokeach 1989).

\section{PEMBAHASAN}

Mister Frimen merupakan sebuah serial web animasi Rusia yang namanya berdasarkan dari tokoh pada film tersebut. Berbeda dari serial animasi film pada umumnya, animasi ini berisi monolog yang disampaikan oleh satu tokoh saja yaitu Mister Frimen itu sendiri, yang mana bentuk dari gambar-gambar yang dihadirkan sangat sederhana dan berwarna monoton, hitam putih. Namun, isi monolog yang disampaikan bersifat filosofis dan mengandung banyak simbol-simbol tertentu. Dalam akun Youtube Mister Frimen, film kartun ini telah memiliki berbagai akun Youtube yang berbeda 


\section{CAPTURE}

dengan versi bahasa yang berbeda juga yaitu versi bahasa Rusia, Ukraina, Inggris, Spanyol, dan Jerman.

Selanjutnya, untuk melihat bagaimana animator memunculkan permasalahan sosial yang nantinya akan terbentuk menjadi sebuah kritik, maka peneliti menganalisis naskah dan beberapa tangkapan gambar adegan terpilih yang berkaitan dari film animasi tersebut dengan teori intertekstual yang digabung dengan metode analisis wacana. Berikut ini pembahasannya.

\subsection{Kritik terhadap Masyarakat Rusia: Permasalahan Sosial dan Aksi Protes}

Jika melihat kembali rekam jejak sejarahnya, Rusia memang selalu bermasalah mengenai kebebasan berekspresi dan memiliki catatan buruk dalam mengkriminalisasi serta menuntut kebebasan berpikir dan berbicara (Beschastna, 2014). Oleh karena itu, aksiaksi protes dan demonstrasi yang dilakukan oleh sebagian masyarakat Rusia mulai terjadi. Maida (2017) juga menekankan bahwa aksi-aksi protes seperti itu sudah ada sejak 2011-2012 saat Vladimir Putin kembali ke kursi kepresidenan. Selain itu, jejaring sosial juga sangat berpengaruh dalam adanya mobilisasi mengenai protes massa yang mulai muncul pada tahun 2011-2012 (Denisova, 2017). Dari permasalahan tersebut, salah satu akar yang paling kuat adalah adanya fungsi utama sebuah katakata. Hal tersebut dapat menjadi sebuah contoh bahwa kata-kata memiliki peranan penting dalam menggiring sebuah opini publik yang berujung adanya propaganda. Hal itu dapat dilihat pada kalimat di bawah ini.

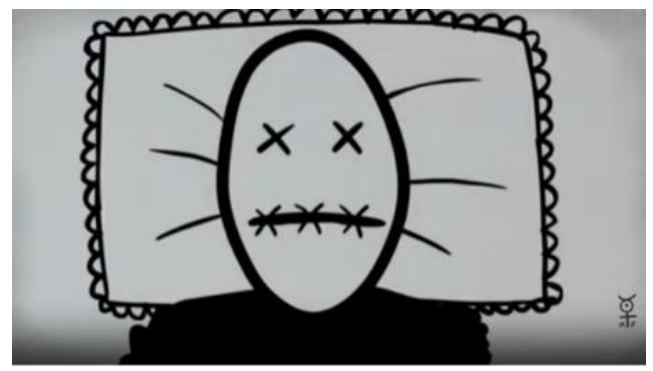

Gambar 1. Mister Frimen yang sedang berbaring dengan keadaan bibir terjahit

(Sumber: Episode 59 Mister Frimen, Timecode: 00:00:01)

\begin{tabular}{|l|l|l|}
\hline \multicolumn{1}{|c|}{$\begin{array}{c}\text { Bahasa } \\
\text { Rusia }\end{array}$} & \multicolumn{1}{|c|}{$\begin{array}{c}\text { Translite- } \\
\text { rasi }\end{array}$} & \multicolumn{1}{|c|}{ Terjemahan } \\
\hline $\begin{array}{l}\text { Вы } \\
\text { заметили, } \\
\text { что }\end{array}$ & $\begin{array}{l}\text { Vy zametili, } \\
\text { čto }\end{array}$ & $\begin{array}{l}\text { Pernahkah } \\
\text { kamu }\end{array}$ \\
$\begin{array}{l}\text { происходиodit } \\
\text { со } \\
\text { словами? }\end{array}$ & so slovami? & $\begin{array}{l}\text { memperhatikan } \\
\text { apa yang terjadi } \\
\text { dengan kata- }\end{array}$ \\
\hline
\end{tabular}

Kalimat di atas dijumpai pada pembukaan episode 59, di mana Mister mencoba untuk mengajak para penontonnya agar membuka pikirannya dan berfikir bersama mengenai fungsi dan kekuatan di balik sebuah kata-kata. Namun, permasalahan mulai muncul pada kalimat selanjutnya. 


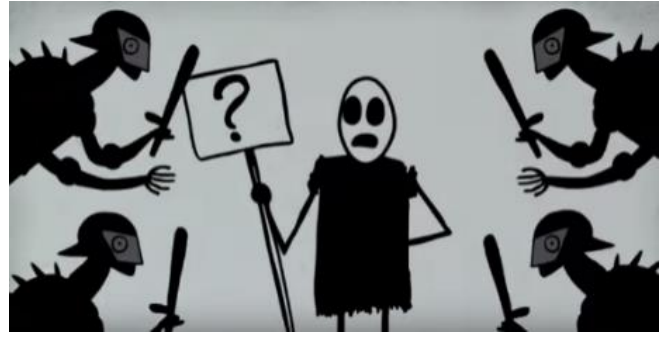

Gambar 2. Mister Frimen yang sedang mengutarakan pendapatnya dan aparat kepolisian yang sedang mengepungnya

(Sumber: Episode 59, Mister Frimen, Timecode: 00.00.29)

\begin{tabular}{|c|c|c|}
\hline $\begin{array}{c}\text { Bahasa } \\
\text { Rusia }\end{array}$ & $\begin{array}{l}\text { Translite- } \\
\text { rasi }\end{array}$ & Terjemahan \\
\hline $\begin{array}{l}\text { Но } \\
\text { знаете, в } \\
\text { чём }\end{array}$ & $\begin{array}{l}\text { No znaete, } \\
\text { v čëm } \\
\text { problema? }\end{array}$ & $\begin{array}{l}\text { Tapi, tahukah } \\
\text { kamu apa } \\
\text { masalahnya? }\end{array}$ \\
\hline $\begin{array}{l}\text { проблема? } \\
\text { Они } \\
\text { вообще } \\
\text { ничего не } \\
\text { значат!!! }\end{array}$ & $\begin{array}{l}\text { Oni voobŝe } \\
\text { ničego ne } \\
\text { značat!!! }\end{array}$ & $\begin{array}{lr}\text { Mereka } & \text { sama } \\
\text { sekali } & \text { tidak } \\
\text { berarti } & \text { apa- } \\
\text { apa!!! } & \end{array}$ \\
\hline
\end{tabular}

Pada teks di atas, dapat dimaknai bahwa keadaan sebuah kata-kata sudah tidak mempunyai fungsi yang berguna. Jika dihubungkan dengan konteks permasalahan sosial yang terjadi sebelum pada tahun 2017 saat episode ini dirilis di Youtube, teks tersebut seolah menggambarkan permasalahan sosial mengenai aksi-aksi protes dan kritik-kritik mengenai kinerja pemerintah yang digembar-gemborkan oleh para oposisi dan aktivis. Dapat dipahami bahwa pada umumnya, permasalahan di masyarakat modern ini adalah senang mengeluarkan sebuah pendapat dan sebuah komentar tentang sesuatu atau kebijakan pemerintahan dan kinerja mereka, tetapi tidak dengan secara bijak (asal bicara), sehingga kata-kata tersebut menjadi tidak berguna dan orang-orang yang seperti itu merupakan orang-orang yang mudah terhasut.

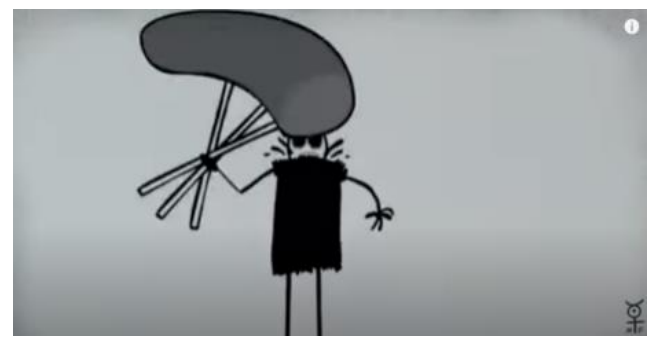

Gambar 3. Mister Frimen yang menyakiti dirinya sendiri dengan memukul kepalanya berulang kali (Sumber: Episode 59 Mister Frimen, Timecode: (00.01.50)

\begin{tabular}{|c|c|c|}
\hline $\begin{array}{c}\text { Bahasa } \\
\text { Rusia }\end{array}$ & $\begin{array}{l}\text { Translite- } \\
\text { rasi }\end{array}$ & Terjemahan \\
\hline $\begin{array}{l}\text { Лиши веса } \\
\text { слова - и } \\
\text { весь мир } \\
\text { преврати } \\
\text { тся в } \\
\text { бордель и } \\
\text { цирк! }\end{array}$ & $\begin{array}{l}\text { Liši vesa } \\
\text { slova - } i \\
\text { ves' mir } \\
\text { prevratitsâ } \\
\text { v bordel' i } \\
\text { cirk! }\end{array}$ & $\begin{array}{l}\text { Singkirkan bobot } \\
\text { dari sebuah kata } \\
\text { dan seluruh } \\
\text { duniar akan } \\
\text { berubah menjadi } \\
\text { rumah bordil dan } \\
\text { sirkus. }\end{array}$ \\
\hline
\end{tabular}

Selanjutnya, merujuk pada permasalahan yang telah dibahas sebelumnya, kalimat yang diucapkan Mister Frimen pada menit ke 00:01:52 dapat diinterpretasikan bahwa sebuah kata-kata yang semakin kehilangan maknanya akan menyebabkan tatanan sosial menjadi kacau. Di zaman modern ini, selain mengenai komentar-komentar yang tidak berbobot, hal ini juga dapat menggambarkan dan menyinggung tentang berita-berita hoax yang tersebar di kalangan masyarakat melalui sosial media. Salah satunya adalah berita hoax mengenai intervensi Rusia pada pemilihan umum AS: 


\section{CAPTURE}

On November 7, 2016, Donald Trump was elected President of the United States after a bitterly fought campaign against Hillary Clinton. The election was very closely-run, with Hillary Clinton winning the popular vote, but losing the presidency based on the U.S electoral college structure. However, months after Donald Trump was declared President of the United States, questions remain about the legitimacy of the U.S elections. The central issues are the emergence and use of so-called 'Fake News' and the accusation that Russia, through espionage and online hacking operations, sought to influence the presidential elections to promote Donald Trump and denigrate the reputation of Hillary Clinton. The issues thrown up in the wake of the U.S presidential election have fundamentally undermined trust in the workings of the international media and further damaged U.SRussia relations. A report by the U.S intelligence services accusing Russia of attempting to influence the outcome of the election, prepared for President Obama and published in the election's immediate aftermath, led to the expulsion 1 of 35 Russian diplomats from Washington just days after the results were announced. President Putin, on the other hand, opted not to expel any U.S diplomats from Russia (Lawrence McDonneLL, 2017)

Secara tidak langsung, Mister

Frimen berpendapat bahwa tatanan sosial akan hancur jika fungsi dari kata-kata yang sesungguhnya hilang, karena para masyarakatnya yang tidak bijak dalam menggunakan kata-kata tersebut. Oleh karena itu, pada kalimat di bawah ini, Mister Frimen memberikan sebuah saran:
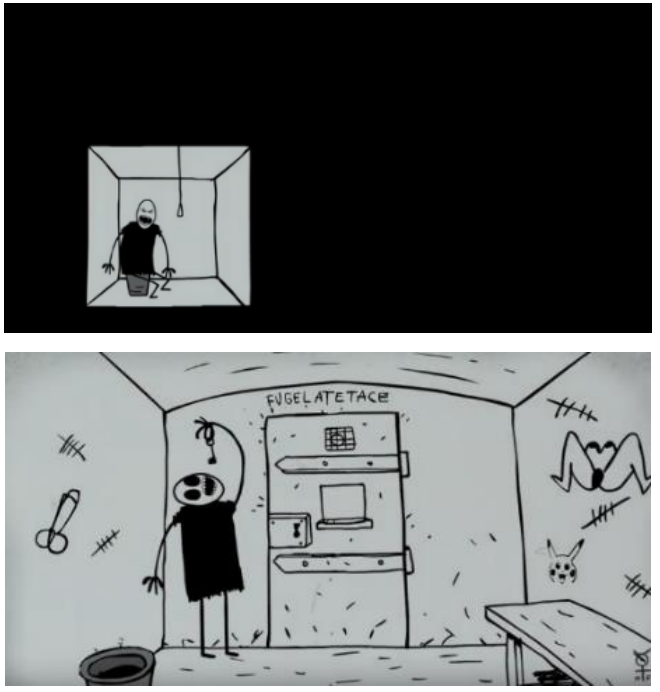

Gambar 4 dan 5. Mister Frimen yang mengurung diri (Sumber: Episode 59 Mister Frimen, Timecode: 00.02.52)

\begin{tabular}{|c|c|c|}
\hline $\begin{array}{l}\text { Bahasa } \\
\text { Rusia }\end{array}$ & $\begin{array}{l}\text { Translite- } \\
\text { rasi }\end{array}$ & Terjemahan \\
\hline $\begin{array}{l}\text { А знаете } \\
\text { что такое } \\
\text { настоящи } \\
\text { й пост? } \\
\text { закрить } \\
\text { свой рот } \\
\text { на замок и } \\
\text { помолчат } \\
\text { ь хотя бы } \\
\text { неделю. }\end{array}$ & $\begin{array}{l}\text { A znaete } \\
\text { čto takoe } \\
\text { nastoâsiji } \\
\text { post? } \\
\text { zakrit' svoj } \\
\text { rot na } \\
\text { zamok i } \\
\text { pomolčat' } \\
\text { hotâ by } \\
\text { nedelû. }\end{array}$ & $\begin{array}{l}\text { Apakah kamu } \\
\text { tahu apa } \\
\text { sebenarnya } \\
\text { puasa } \\
\text { (postingan) itu? } \\
\text { kunci mulutmu } \\
\text { dan tutup mulut } \\
\text { setidaknya } \\
\text { selama } \\
\text { seminggu. }\end{array}$ \\
\hline $\begin{array}{l}\text { Нет, вы, } \\
\text { действит } \\
\text { ельно, } \\
\text { хотите } \\
\text { вернуть } \\
\text { вес своим } \\
\text { словами? } \\
\text { Тогда } \\
\text { помолтит } \\
\text { е сем, а } \\
\text { лучше } \\
\text { десять } \\
\text { дней! Не } \\
\text { проронив } \\
\text { ни слова! } \\
\text { Не выходя } \\
\text { в соцсети! }\end{array}$ & $\begin{array}{l}\text { Net, vy, } \\
\text { dejstvitel'n } \\
\text { o, hotite } \\
\text { vernut' ves } \\
\text { svoim } \\
\text { slovami? } \\
\text { Togda } \\
\text { pomoltite } \\
\text { sem, a } \\
\text { lučše } \\
\text { desât' dnej! } \\
\text { Ne } \\
\text { proroniv ni } \\
\text { slova! Ne } \\
\text { vyhodâ v } \\
\text { socseti! }\end{array}$ & $\begin{array}{l}\text { Jadi, apakah } \\
\text { kamu sangat } \\
\text { ingin } \\
\text { memberikan } \\
\text { sebuah makna } \\
\text { pada kata- } \\
\text { katamu lagi? } \\
\text { Kalau begitu, } \\
\text { diamlah selama } \\
7 \text { atau } 10 \text { hari! } \\
\text { Tanpa } \\
\text { mengatakan } \\
\text { satu kata pun! } \\
\text { Atau } \\
\text { berselancar di } \\
\text { jejaring sosial! }\end{array}$ \\
\hline
\end{tabular}


memberikan saran kepada para orangorang tersebut bahwa apabila memang tidak dapat berkomentar atau berpendapat secara bijak, maka salah satu jalan terbaiknya adalah lebih baik diam. Secara tidak langsung kalimat tersebut berasal dari sebuah perumpamaan umum yaitu 'SILENT is GOLD' yang berarti bahwa berkatalah yang baik atau lebih baik diam jika tidak tahu sama sekali. Jadi, Mister Frimen menyarankan bahwa diam dapat berdampak baik pada kesejahteraan bersama.

Jika dikaitkan dengan konteks tentang unjuk rasa yang terjadi baru-baru ini, pesan tersirat yang muncul dalam episode ini adalah Mister Frimen secara tidak langsung mencoba menyindir dan mengkritik masyarakat Rusia yang ikut aksi dalam unjuk rasa baik itu unjuk rasa secara offline (tidak langsung atau terjun langsung dalam aksi tersebut) maupun online (ikut ambil bagian dalam aksi protes tersebut tetapi melalui sosial media). Mister Frimen menyindir masyarakat modern saat ini tentang perlu bijaknya dalam berpendapat dan berkomentar.

\section{SIMPULAN}

Seluruh individu memiliki perannya masing-masing. Para pembuat Mister Frimen dengan sadar menggunakan peran mereka sebagai masyarakat untuk menghasilkan dampak tertentu terhadap kontrol sosial di Rusia. Hal ini dibuktikan dengan lahirnya Mister Frimen sebagai gambaran realitas yang ada di lingkup masyarakat Rusia pada era Federasi Rusia. Hasil penelitian pada episode 59 ini tampak bahwa para pembuat film ini mengkritik masyarakat Rusia modern dengan memunculkan satu permasalahan sosial yaitu mengenai aksi protes dan penyebaran berita hoax yang disampaikannya melalui tokoh Mister Frimen. Namun, walaupun menyindir orang-orang tersebut, pembuat film ini juga memberikan saran agar kedamaian dan kesejahteraan dalam masyarakat tetap seimbang dan terjaga yaitu dengan cara diam apabila memang tidak mengetahui masalah yang sebenarnya.

Permasalahan sosial dalam film ini terbaca melalui pencocokan berita dan informasi mengenai kejadian sosial yang dengan data-data yang diperoleh dan pengetahuan yang dimiliki oleh peneliti, sehingga terbukti bahwa satu teks dengan teks yang lain saling berkaitan seperti pendapat yang telah dikemukakan oleh Julia Kristeva mengenai intertekstualitas. Satu sumber teks berfungsi signifikan untuk memaknai sumber teks lainnya, sehingga akan menghasilkan pengertian dan pemahaman yang baru. Pada film ini terbukti bahwa pesan-pesan yang disampaikan oleh tokoh berwarna hitamputih tersebut terbentuk dari permasalahan sosial yang terjadi dalam masyarakat baik itu masalah yang secara langsung dilihat dan dialami oleh pembuat Mister Frimen 


\section{CAPTURE}

maupun masalah yang telah diulas dalam sebuah data seperti berita dan pengetahuan yang dimiliki oleh peneliti turut membantu dalam memaknai pesanpesan yang ada.

\section{DAFTAR ACUAN}

Asmolov, Gregory. (2010). Russia: Online Cartoon Character - Mr. Freeman Deconstructs Reality, Mocks Netizens. Retrieved January, 27, 2020, https://www.academia.edu

Beumers, Brigit. (2005). Pop Culture Russia!: Media, Arts, and Lifestyle. California: ABC-CLIO, Inc.

Beschastna, T. (2014) 'Freedom of Expression in Russia as it Relates to Criticism of the Government', Emory International Law Review, $27,2$.

Denisova, A. (2017). Democracy, Protest and Public Sphere in Russia after the 2011-2012 anti-Government Protests: Digital Media at Stake. Media, Culture \& Society, 39(7), 976-994.

Elmo Raj, P. (2015). "Text/Texts: Julia Kristeva's Concept of Intertextuality", Ars Artium: An International Peer Reviewed-cumRefereed Research Journal of Humanities and Social Sciences, Vol.3, 78.

Eriyanto. (2013). Analisis Naratif: Dasardasar dan Penerapannya dalam Analisis Teks Berita Media. Jakarta: PT Interpratama Mandiri.

Fiske, John. (1987). Television Culture. Padstow, Cornwall: TJ International Ltd.

Kuswarini, Prasuri. (2016). "Penerjemahan, Intertekstualitas, Hermeneutika dan Estetika Resepsi”. Jurnal Ilmu Budaya, 4.1.

Kristeva, Julia. (1980). Desire in Language: A Semiotic Approach to
Literature and Art. Trans. Thomas Gora, Alice Jardine and Leon S. Roudiez, ed. Leon S. Roudiez. New York: Columbia University Press.

Maida, Adam. (2017). Online and On All Fronts Russia's Assault on Freedom of Expression. Retrieved May, 17, 2020, https://www.hrw.org/report/

McDonneLL, Lawrence. (2017). Lies, Spies and Big Data: How Fake News Is Rewriting Political Landscapes. Russian International Affairs Council

Melvin L. Defleur, Sandra Ball-Rokeach. (1989). Theories of Mass Communication. White Plains: Longman.

Mr. Freeman. (2017). Mr Freeman, part 59, https://www.youtube.com/

Ott, B.L., \& Walter, C.K. (2000). "Intertextuality: Interpretive Practice and Textual Strategy". Critical Studies in Media Communication, 17, 429 - 446.

Pontieri, Laura. (2006). Russian Animation of The 1960s and The Khrushchev Thaw. Amerika Serikat: Yale University.

Sugihartono, Ranang Agung dkk. (2010). Animasi Kartun: Dari Analog Sampai Digital. Jakarta: Penerbit Indeks.

Wellek, R. (1992). "The Essential Characteristics of Russian Literary Criticism". Comparative Literature Studies, 29(2), 115-140.

Publisher:

Jurusan Seni Media Rekam

Fakultas Seni Rupa dan Desain

Institut Seni Indonesia (ISI) Surakarta

Available online at:

https://jurnal.isi-ska.ac.id/index.php/capture

How to Cite:

Ristiasari, Riska \& Kaprisma, Hendra. (2021). Social

Criticism in the Mister Frimen Animated Series.

CAPTURE: Jurnal Seni Media Rekam, 12(2), 176-

188. 